06

\title{
Синтез гексагональных слоев AIN и GaN на Si(100)-подложке методом хлоридной газофазной эпитаксии
}

\author{
(C) В.Н. Бессолов, ${ }^{1}$ Е.В. Гущина, ${ }^{1}$ Е.В. Коненкова, ${ }^{1}$ С.Д. Коненков, ${ }^{2}$ Т.В. Львова, ${ }^{1}$ \\ В.Н. Пантелеев, ${ }^{1}$ М.П. Щеглов ${ }^{1}$ \\ ${ }^{1}$ Физико-технический институт им. А.Ф. Иоффре РАН, \\ 194021 Санкт-Петербург, Россия \\ ${ }^{2}$ Санкт-Петербургский государственный университет, \\ 198504 Петергофр, Санкт-Петербург, Россия \\ e-mail: lena@triat.ioffe.rssi.ru
}

(Поступило в Редакцию 16 апреля 2018 г.)

Рассмотрена технология синтеза $\mathrm{AlN}$ - и $\mathrm{GaN}$-структур на $\mathrm{Si}(100)$-подложке методом хлоридной газофазной эпитаксии, включающей в себя сульфидирование поверхности кремния, зарождение и рост AlN-слоя, а затем $\mathrm{GaN} / \mathrm{AlN}$-структуры. Обнаружено, что синтез GaN происходит на буферных слоях двух кристаллографических ориентаций AlN на подложке $\operatorname{Si}(100)$ по сравнению с одной кристаллографической ориентацией на подложке $\mathrm{Si}(111)$. Показано, что применение водных растворов $\left(\mathrm{NH}_{4}\right)_{2} \mathrm{~S}$ при обработке $\mathrm{Si}(100)$ приводит к уменьшению полуширины рентгеновской кривой качания $\mathrm{GaN}(0002)$ в 1.5 раза.

DOI: $10.21883 /$ JTF.2019.04.47315.152-18

\section{Введение}

Нитриды алюминия и галлия являются перспективными материалами для создания приборов УФ-оптоэлектроники, мощной, высокочастотной и биосенсорной электроники.

Среди различных материалов подложек $\left(\mathrm{Al}_{2} \mathrm{O}_{3}, \mathrm{SiC}\right.$, $\mathrm{Si})$ для гетероэпитаксии III-нитридов кремний является наиболее привлекательным. Прежде всего, это обусловлено возможностью использования подложек большого диаметра (до $300 \mathrm{~mm}$ ), их низкой стоимостью, высокой электрической и тепловой проводимостью. Использование $\mathrm{Si}(100)$ в качестве подложки для эпитаксии слоев III-N-полупроводников является предпочтительней из-за возможной интеграции нитрид-галлиевой и кремниевой электроники. Пионеры формирования слоев нитрида галлия на кремнии предложили [1] синтезировать $\mathrm{GaN}$ вначале на подложке $\mathrm{Si}(111)$, а затем механически перенести его на $\mathrm{Si}(100)$ с удалением $\mathrm{Si}(111)$, но предпочтительнее попытаться синтезировать GaN непосредственно на $\mathrm{Si}(100)$ с использованием $\mathrm{AlN}$ в качестве буферного слоя.

Как известно, [2] слои AlN формируются на подложке $\mathrm{Si}(100)$ в виде столбчатых доменов. Этот результат не удивителен, зная, что $\operatorname{Si}(001)$ и $\operatorname{AlN}(0001)$ имеют большое различие постоянных решеток и разную кристаллографическую симметрию сопрягающихся плоскостей [3]. При эпитаксии AIN на $\mathrm{Si}(100)$ методом хлоридной газофазной эпитаксии (HVPE) отмечено, что возможно существование гексагональных доменов, развернутых на $30^{\circ}$ по отношению друг к другу, что связано с реконструкцией поверхности $\mathrm{Si}(100)$, а именно $\mathrm{Si}(2 \times 1)$ и $\mathrm{Si}(1 \times 1)[4]$. Известно, что синтез $\mathrm{AlN}$ и $\mathrm{GaN}$ на $\mathrm{Si}(100)$ приводит к поликристаллическим или текстурным слоям, по крайней мере, с очень грубыми поверхностями, состоящих из многих зерен [5]. Обычно для повышения качества слоев гексагонального AlN используют разоринтированные в направлении на $4-7^{\circ}$ подложки $\mathrm{Si}(100)$, однако разориентированные $\mathrm{Si}(100)$-подложки не применимы в технологии кремниевой микроэлектроники, поскольку затруднено формирование воспроизводимого микрорельефа поверхности, обладающего необходимыми характеристиками [6]. В работах, посвященных синтезу $\mathrm{AlN}, \mathrm{GaN}$ на подложке $\mathrm{Si}(100)$, как правило, использовали разориентированные подложки $\mathrm{Si}(100)$ : так $\mathrm{AlN}$ синтезировали методами молекулярной лучевой эпитаксии (MBE) [7], магнетронного напыления [2], HVPE [4]; а GaN с буферным слоем нитрида алюминия синтезировали методами импульсного лазерного осаждения (PLD) [8], MBE [9], HVPE [10] и металло-органической гидридной эпитаксией MOCVD [11]. Однако по сравнению со слоями $\mathrm{GaN}$ на подложке $\mathrm{Si}(111)$ качество слоев $\mathrm{GaN}$ на $\mathrm{Si}(100)$ не высоко.

Одной из проблем зарождения и роста слоев $\mathrm{AlN}$ на кремниевой подложке является нежелательное наличие на поверхности оксидов кремния. Как известно [12], эффективным методом удаления оксидов с поверхности полупроводников $\mathrm{A}^{3} \mathrm{~B}^{5}$ является химическая халькогенидная пассивации, которая успешно применяется, главным образом, на кристаллах GaAs, GaSb, InAs. Обработка водными растворами $\left(\mathrm{NH}_{4}\right)_{2} \mathrm{~S}$ приводит к удалению оксидного слоя с поверхности $\mathrm{A}^{3} \mathrm{~B}^{5}$ полупроводников и формированию на ней сульфидного пассивирующего покрытия. Имеются сведения об использовании водных растворов $\left(\mathrm{NH}_{4}\right)_{2} \mathrm{~S}$ для пассивации поверхностей $\operatorname{GeSi}(100)$ [13] и $\mathrm{Si}(100)$ [14]. Работ, посвященных использованию $\left(\mathrm{NH}_{4}\right)_{2} \mathrm{~S}$ для синтеза слоев нитрида галлия с буферным слоем нитрида алюминия на подложке $\mathrm{Si}(100)$, в литературе мы не обнаружили. 
Настоящая работа и посвящена синтезу гексагональных слоев $\mathrm{GaN}$ на $\mathrm{Si}(100)$ подложке методом HVPE при обработке подложек в водном растворе сульфида аммония $\left(\mathrm{NH}_{4}\right)_{2} \mathrm{~S}$.

\section{Методика эксперимента}

В экспериментах использовались подложки кремния $n$-типа с разориентацией поверхности не более $10 \mathrm{arcmin}$. В процессе предэпитаксиальной подготовки поверхность подложек очищалась ацетоном (осч) в ультразвуковой ванне в течение 5 min. Затем одна группа подложек $\mathrm{Si}(100)$ травилась в разбавленном растворе $\mathrm{HF}$, а другая - обрабатывалась концентрированным $(\sim 6 \mathrm{M})$ водным раствором $\left(\mathrm{NH}_{4}\right)_{2} \mathrm{~S}$ при температуре $40-50^{\circ} \mathrm{C}$ в течение $4 \mathrm{~min}$. После окончания процесса сульфидизации образцы промывались в проточной дистиллированной воде и высушивались на воздухе при комнатной температуре. Эпитаксиальное выращивание слоев в начале AlN, а затем GaN/AlN осуществлялось методом HVPE на $\mathrm{Si}(100)$ - и для сравнения на $\mathrm{Si}(111)$-подложках аналогично [15]. Температура эпитаксии AlN составляла $1080^{\circ} \mathrm{C}$, a $\mathrm{GaN}-1050^{\circ} \mathrm{C}$, и со скоростью потоков $\mathrm{HCl}$ и $\mathrm{NH}_{3}-$ 1.7 и 2.41/min соответственно.

Структуры AlN/Si(100), AlN/Si(111) и GaN/AlN/Si(100) исследовались методами рентгеновской дифрактометрии. Кривые качания регистрировались для симметричного (0002) брэгговского рефлекса в режиме двухкристальной $(\omega)$-скан схемы дифракции. Рельеф поверхности слоев AlN контролировался с помощью атомно-силовой микроскопии (АСM) в атмосферных условиях, а слоев $\mathrm{GaN}$ - сканирующей электронной микроскопией (СЭМ).

\section{Экспериментальные результаты}

Ренгенодифракционные измерения AlN- и GaN-слоев, показали, что величина FWHM-кривых для брэгговского рефлекса $\mathrm{AlN}(0002)$ составляет $100 \mathrm{arcmin}$, a $\mathrm{GaN}(0002)$ - $120 \operatorname{arcmin}$ для слоев, синтезированных на сульфидированной подложке, и около $180 \operatorname{arcmin}$ и 200 arcmin соответственно на подложках без сульфидной обработки.

Из сравнения СЭМ-изображений поверхностей $\mathrm{GaN}$ следует, что обработка в сульфидном растворе приводит к синтезу слоя $\mathrm{GaN}$ с меньшим размером блоков и более гладкой поверхностью по сравнению со слоем, синтезированном на подложке без сульфидной обработки (рис. $1, a, b)$.

Сравнение АСМ-изображений поверхностей слоев AlN, синтезированных на подложках $\mathrm{Si}(100)$, показало, что на начальной стадии роста формируется поликристаллическая структура на необработанной подложке. После обработки $\mathrm{Si}(100)$ в сульфидном растворе наблюдается формирование столбов (рис. 2, $b$ ) в основном двух кристаллографических ориентаций - AlN-I
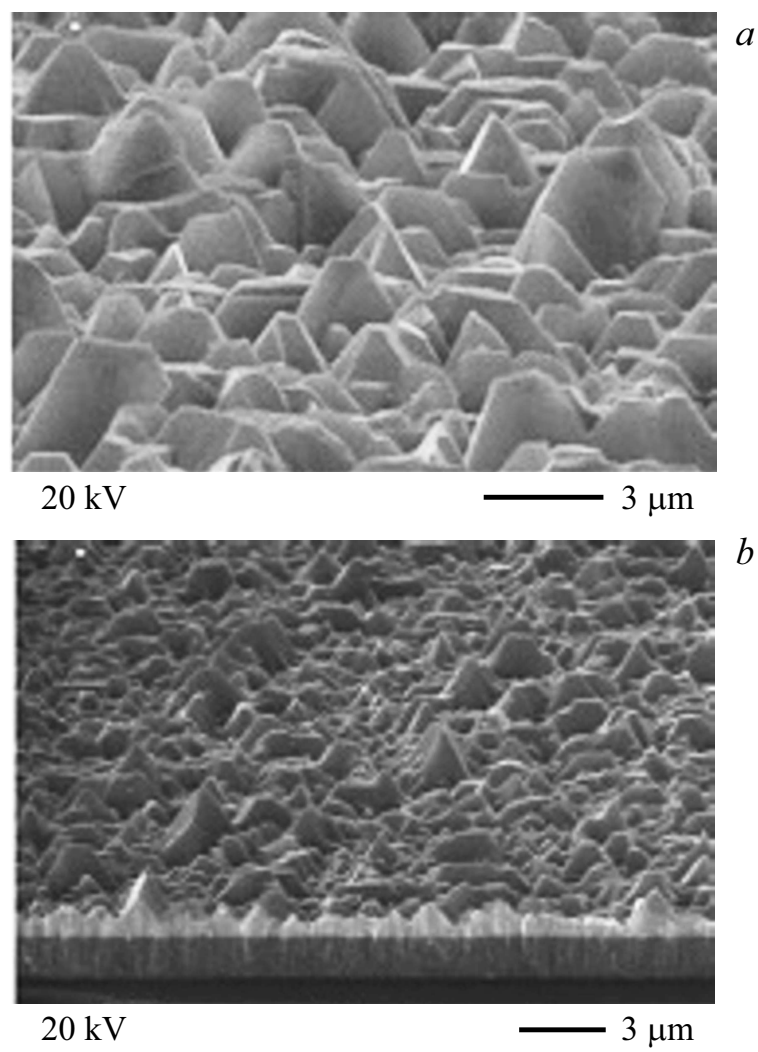

Рис. 1. СЭМ-изображения поверхности структуры $\mathrm{GaN} / \mathrm{AlN} / \mathrm{Si}(100)$ : без сульфидной обработки (a) и после обработки $(b)$.

и AlN-II (рис. 2, $a, d$ ). АСМ-изображение поверхности слоя AlN, синтезированного на подложке $\mathrm{Si}(111)$, показало, что формируются гексагональные столбы (рис. 2,c) только одного типа кристаллографической ориентации - AlN I (рис. 2,e).

Как известно, поверхностные атомы кремния при адсорбции кислорода легко окисляются, так как энергия химической связи $\mathrm{Si}-\mathrm{O}$ более чем в 2 раза превышает энергию химической связи между атомами кремния. При окислении граница раздела $\mathrm{Si}-\mathrm{SiO}_{2}$ двигается в глубь кремниевой подложки и, поскольку лимитирующим фактором является недостаток свободного объема для образования оксида, граница $\mathrm{Si}-\mathrm{SiO}_{2}$ представляет собой напряженную гетероструктуру с неоднородными по толщине и структуре слоями оксида кремния. Как известно, раствор $\left(\mathrm{NH}_{4}\right)_{2} \mathrm{~S}$ является термически нестабильным при температурах более $40^{\circ} \mathrm{C}$ и распадается на $\left(\mathrm{NH}_{4}\right) \mathrm{OH}$ и атомы $\mathrm{S}$, а в свою очередь растворы $\left(\mathrm{NH}_{4}\right) \mathrm{OH}$ успешно удаляют оксиды [14].

Зарождение эпитаксиального слоя AlN на подложке $\mathrm{Si}$ зависит от наличия оксидов на ее поверхности. Использование сульфидной обработки поверхности должно приводить к удалению окислов кремния, и в результате обработки водным раствором сульфида аммония с поверхности $\mathrm{Si}(100)$ удаляется слой естественного окисла 


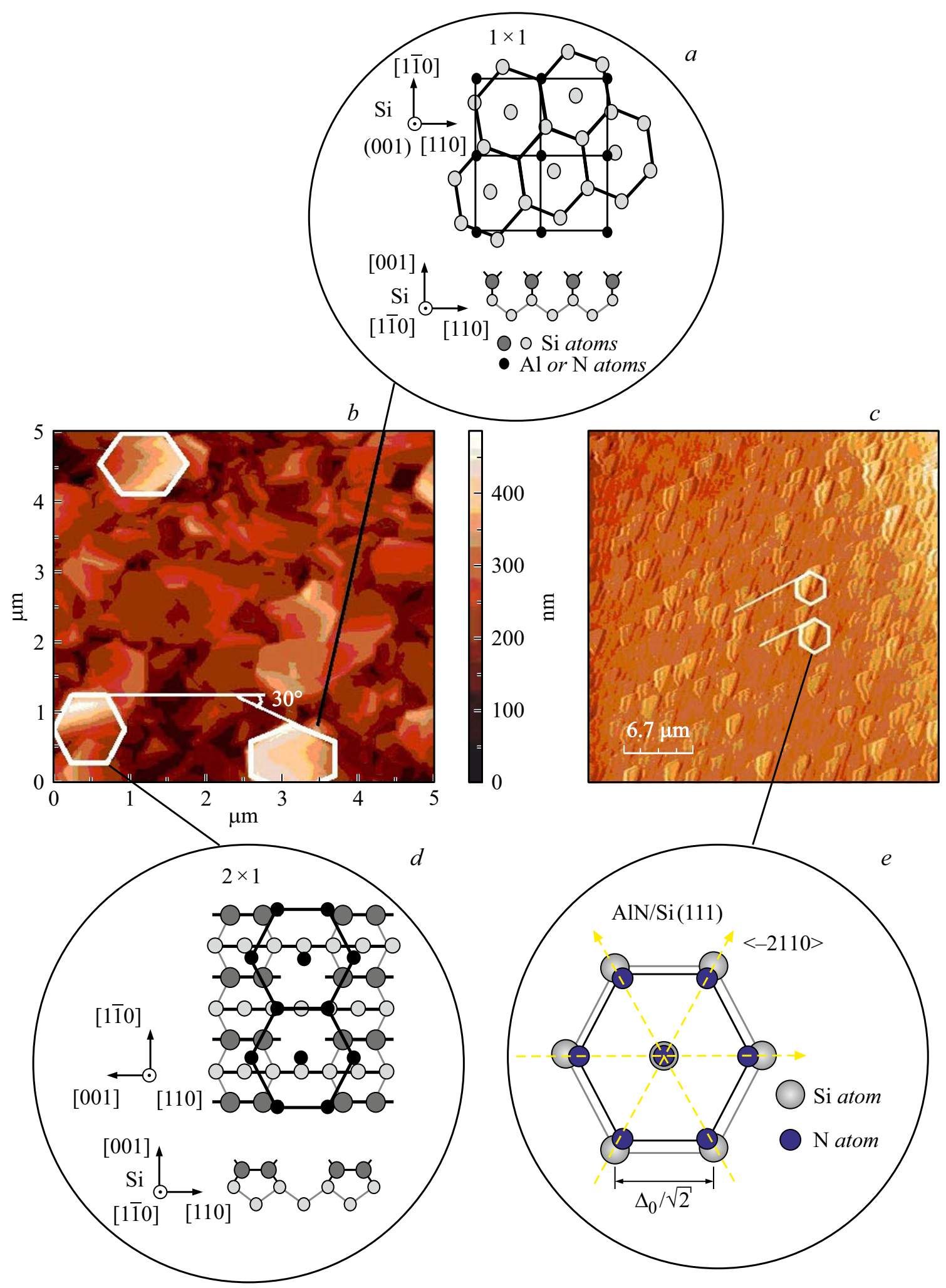

Рис. 2. Схематическое изображение сопряжения $\mathrm{AlN}$ на $\mathrm{Si}(1 \times 1)(a), \operatorname{Si}(2 \times 1)(d)$ и $\mathrm{Si}(111)(e)$ и АСМ-изображения поверхностей $\operatorname{AlN}(0001)$ на подложках $\operatorname{Si}(100)(b)$ и $\operatorname{Si}(111)(c)$.

вместо которого формируется сплошной хемосорбционный пассивирующий слой из атомов серы, когерентно связанных с атомами кремния. Как мы предполага- ем, при химическом взаимодействии неоднозначного по толщине слоя $\mathrm{SiO}_{2}$ с $\left(\mathrm{NH}_{4}\right) \mathrm{OH}$ происходит удаление части оксида и формирование сульфидного слоя, причем 
возможно формирование двух типов поверхностных решеток $\operatorname{Si}(2 \times 1)$ и $\mathrm{Si}(1 \times 1)$. Зарождение $\mathrm{AlN}$ на $\mathrm{Si}(100)$ с поверхностной решеткой $(2 \times 1)$ и $(1 \times 1)$ в свою очередь приведет к формированию столбчатых структур AlN двух ориентаций (рис. 2, $a, d$ ).

Наличие двух столбчатых зародышей $\mathrm{AlN}$, развернутых относительно друг друга, и приводит к уширению рентгеновской кривой дифракции структур для $\mathrm{GaN} / \mathrm{AlN} / \mathrm{Si}(100)$ по сравнению с данными для структур $\mathrm{GaN} / \mathrm{AlN} / \mathrm{Si}(111)$, для которых характерно формирование зародышей одной криталлографической ориентации.

Для выяснения роли сульфидной обработки поверхности $\mathrm{Si}(100)$ мы сравнили данные рентгеноструктурного анализа структур $\mathrm{AlN} / \mathrm{Si}(100)$ и $\mathrm{GaN} / \mathrm{Si}(100)$, полученные другими методами. Оказалось, что методом MBE удалось вырастить $\mathrm{AlN}(0001)$ толщиной $500 \mathrm{~nm}$ на разориентированной на $4^{\circ}$ подложке $\operatorname{Si}(100)$ с $\omega_{2 \Theta}=0.273^{\circ}$, а на ориентированной подложке $\operatorname{Si}(100)$ с $\omega_{2 \Theta}=0.54^{\circ}$ [2]. Методом магнетронного распыления удалось получить слой $\mathrm{AlN}(0002)$ на ориентированной подложке $\operatorname{Si}(100)$ с $\omega_{2 \Theta}=1.7^{\circ}[16]$, что не превосходит данных, полученных нами. Сравнения величин FWHM брэгговского рефлекса $\mathrm{GaN}(0002)$, синтезированных методом HVPE на $\mathrm{Si}(100)$ [10], с нашими данными показали уменьшение этой величины примерно в 1.5 раза при использовании сульфидной обработки.

\section{Заключение}

Таким образом, установлено, что величина FWHM кривых для брэгговского рефлекса $\mathrm{AlN}(0002)$ составлет $100 \operatorname{arcmin}$, a $\mathrm{GaN}(0002)$ - $120 \operatorname{arcmin}$, в слоях, синтезированных на сульфидированных подложках $\mathrm{Si}(100)$. ACМ-измерения показали, что на начальных стадиях роста происходит зарождение двух кристаллографических ориентаций гексагонального нитрида алюминия на подложке $\mathrm{Si}(100)$ по сравнению с формированием одной ориентации на подложке $\mathrm{Si}(111)$. Предложенная технология синтеза методом хлоридной газофазной эпитаксией GaN/AlN-структур, включающая в себя сульфидирование поверхности $\mathrm{Si}(100)$-подложки, является перспективным методом синтеза нитрида галлия на кремнии.

\section{Список литературы}

[1] Xiong C., Pernice W., Ryu K.K., Schuck C., Fong K.Y., Palacios T., Tang H.X. // Opt. Express. 2011. Vol. 19. N 11. P. 10462-10470.

[2] Valcheva E., Birch J., Persson P.O.A., Tungasmita S., Hultman L. // J. Appl. Phys. 2006. Vol. 100. N 12. P. 123514(1-6).

[3] Dadgar A., Schulze F., Wienecke M., Gadanecz A., Bläsing J., Veit P., Hempel T., Diez A., Christen J., Krost A. // New J. Physics. 2007. Vol. 9. P. 389(1-10).
[4] Бессолов В.Н., Гущина Е.В., Коненкова Е.В., Львова Т.В., Пантелеев В.Н., Щеглов М.П. // Письма в ЖТФ. 2018. T. 44. N 2. C. 96-103. [Bessolov V.N., Gushchina E.V., Konenkova E.V., L'vova T.V., Panteleev V.N., Shcheglov M.P. // Tech. Phys. Lett. 2018. Vol. 44. N 1. P. 81-83.]

[5] Zhang X., Hou Y.-T., Feng Z.-C., Chen J.L. // J. Appl. Phys. 2001. Vol. 89. N 11. P. 6165-6170.

[6] Атомная структура полупроводниковых систем / Под ред. А.М. Асеева. Новосибирск: СО РАН, 2006. 292 с.

[7] Lebedev V., Jinschek J., Kräußlich J., Kaiser U., Schröter B., Richter W. // J. Cryst. Growth. 2001. Vol. 230. N 3. P. 426-431.

[8] Wang W.K., Jiang M.-C. // Jpn. J. Appl. Phys. 2016. Vol. 55. P. 095503(1-4).

[9] Gerbedoen J.-C., Soltani A., Joblot S., DeJaeger J.-C., Gaquiére Ch., Cordier Y., Semond F. // IEEE Transactions on Electron Devices. 2010. Vol. 57. N 7. P. 1497-1503.

[10] Kim S.T., Lee Y.J., Chung S.H., Moon D.C. // J. Korean Phys. Soc. 1998. Vol. 33. P. S313-S315.

[11] Schulze F., Dadgar A., Bläsing J., Krost A. // Appl. Phys. Lett. 2004. Vol. 84. N 23. P. 4747-4749.

[12] Бессолов В.Н., Лебедев М.В. // ФТП. 1998. Т. 32. $\mathrm{N}$ 11. C. 1281-1299. [Bessolov V.N., Lebedev M.V. // Semiconductors. 1998. Vol. 32. N 11. P. 1141-1156.]

[13] Heslop S.L., Pecklor L., Muscat A.J. // ECS Transactions. 2017. Vol. 80. N 2. P. $147-153$.

[14] Ali M.Y., Tao M. // Electrochem. Sol. Stat. Lett. 2007. Vol. 10-11. P. H317.

[15] Бессолов В.Н., Давыдов В.Ю., Жиляев Ю.В., Коненкова Е.В., Мосина Г.Н., Раевский С.Д., Родин С.Н., Шарофидинов Ш., Щеглов М.П., Park H.S., Koike M. // Письма в ЖТФ. 2005. Т. 31. Вып. 21. С. 30-36. [Bessolov V.N., Davydov V.Yu., Zhilyaev Yu.V., Konenkova E.V., Mosina G.N., Raevski S.D., Rodin S.N., Sharofidinov Sh., Shcheglov M.P., Park H.S., Koike M. // Tech. Phys. Lett. 2005. Vol. 31. N 11. P. 915-918.]

[16] Lin C.-M., Lien W.-C., Felmetsger V.V., Hopcroft M.A., Senesky D.G., Pisanoless A.P. // Appl. Phys. Lett. 2010. Vol. 97. N 14. P. $141907(1-3)$. 